\title{
Sentidos do trabalho na percepção de pessoas que exercem trabalho comum
}

\author{
Rosiane Dutra Martins ${ }^{1}$, Priscila Sardi Cerutti², \\ Elem Duarte $\mathrm{Vaz}^{3}$ e Shalimar Gallon ${ }^{4}$ \\ Faculdade Meridional (Passo Fundo, Rio Grande do Sul, Brasil)
}

\begin{abstract}
O trabalho comum é entendido como algo repetitivo, maçante, muitas vezes perigoso, penoso, sujo e fisicamente esgotante. Diante dessas características, ele passa despercebido pela sociedade frente à invisibilidade pública e ao desprestígio social que lhe é atrelado. Para tanto, este estudo busca analisar os sentidos do trabalho para aqueles que exercem esses trabalhos. Por meio de uma pesquisa qualitativa, foram realizadas 32 entrevistas com trabalhadores que exercem trabalhos comuns na região Norte do estado do Rio Grande do Sul. As entrevistas foram realizadas com base em um roteiro semiestruturado, gravadas, transcritas e analisadas por meio da técnica de análise de conteúdo, com o auxílio do software Max-Qda. O trabalho apresentou-se como central na vida dos pesquisados, estando relacionado à sobrevivência, inserção social e ao prazer em realizar as atividades que lhes são atribuídas. Para tanto, independentemente da função que ocupam e do nível de instrução que possuem, o trabalho que exercem tem uma finalidade e um valor para sociedade.
\end{abstract}

Palavras-chave: Sentidos do trabalho, Trabalho comum, Desprestígio social, Relação de trabalho.

Meaning of work in the perception of people who carry out common work

Common work is understood as repetitive, dull, often dangerous, painful, dirty, and physically grueling. In face of these characteristics, the common work goes unnoticed by the society in front of the public invisibility and the social discredit that is attached to it. Therefore, this study seeks to analyze the meaning of work for professionals who carry out common work. Through a qualitative research, 32 interviews were carried out with workers who performed common work in the northern region of the state of Rio Grande do Sul. Interviews were conducted based on a semi-structured script, recorded, transcribed and analyzed using the analysis technique with the help of Max-Qda software. The work presented as central in the life of the researched ones, being related to the survival, social insertion and pleasure in carrying out the activities that are attributed to them. For doing so, regardless of the function they occupy and the level of education they have, the work they carry out has a purpose and a value for society.

Keywords: Meaning of work, Common work, Social discredit, Work relationship.

\section{Introdução}

$\mathrm{C}$ omo consequência das inúmeras transformações do sistema capitalista vivenciadas no último século, o trabalho humano tem sofrido modificações (Wadsworth, Chaplin \& Smith, 2010). Frente à classificação do trabalho em braçal e intelectual; manual e mental; conhecimento informal e formal; e operacional e especializado, é reafirmado um preconceito histórico sobre as atividades laborais que impede de compreender as contribuições socioeconômicas e organizacionais, bem como as implicações individuais do trabalho operacional para os sujeitos que o exercem (Rose, 2007).

Esses trabalhadores realizam tarefas imprescindíveis à sociedade, mas geralmente não são percebidos como seres humanos, e sim como pessoas que realizam atividades que uma pessoa com mais recursos financeiros e melhor instrução não se submeteria (Celeguim \& Roesler, 2009; Costa, 2008).

\footnotetext{
Mestranda em Administração pela Faculdade Meridional (Imed). Empresária no ramo da moda.

Mestra em Administração pela Faculdade Meridional (Imed). Professora na Faculdade Anhanguera, Passo Fundo - RS.

Mestranda em Administração pela Faculdade Meridional (Imed).

Professora e pesquisadora do Programa de Pós-Graduação em Administração da Imed Businnes School (Imed).
} 
Para tanto, o que leva as pessoas a exercerem um trabalho comum - repetitivo, maçante, muitas vezes perigoso, penoso, sujo e fisicamente esgotante (Rose, 2007) - frente à invisibilidade pública e ao desprestígio social da atividade exercida?

Mesmo sendo um trabalho duro, alvo de reclamações, instável e uma ameaça ao corpo e a dignidade, o indivíduo tende a procurar sentido no desenvolvimento da sua atividade, pois tem no trabalho um amparo contra a pobreza, visto que, na sua ausência, as implicações podem ser graves (Rose, 2007). Assim, o trabalho é essencial na vida das pessoas para a manutenção da saúde mental (Morin, 2001), por permitir a sobrevivência (Morin, Tonelli \& Pliopas, 2007), bem como é fonte de satisfação e realização (Morin, 2001), estando relacionado ao reconhecimento por seus pares na organização (Morin et al., 2007). É através dele que o sujeito tem a oportunidade de construir sua identidade, interagir socialmente, encontrar um propósito e desafios, adquirir status e obter renda (Zanelli, Silva \& Soares, 2010).

Mesmo que os apontamentos mencionados sejam atribuídos, de forma geral, a todas as ocupações profissionais, existem variações quanto ao sentido encontrado em cada atividade laboral, ocasionado pela peculiaridade de cada ocupação e pelo tipo de atividade desenvolvida (Silva \& Simões, 2015). Para tanto, cada ocupação oferece distintos riscos, pressões, exigências e esforços, quando comparadas entre si.

Portanto, estudar os sentidos do trabalho torna-se fundamental para entender as implicações das mudanças no comportamento dos indivíduos em seus ambientes de trabalho (Silva \& Simões, 2015). Nesse contexto, este estudo teve como objetivo analisar a percepção sobre os sentidos do trabalho para pessoas que exercem um trabalho comum frente à invisibilidade pública e ao desprestígio social da atividade exercida.

Para isso, apresenta-se na próxima seção estudos sobre o trabalho comum, bem como os sentidos do trabalho para os indivíduos. Após, são elucidados os procedimentos metodológicos da pesquisa, a análise das informações coletadas e as considerações finais.

\section{O trabalho comum}

Ao adotar a perspectiva sociológica, Rose (2007, p. 40) entende que o trabalho pode ser compreendido como "um esforço intencional, remunerado e que fornece mercadorias ou serviços a terceiros" e, do ponto de vista humano, implica na mobilização da inteligência, na capacidade de refletir, interpretar e reagir às situações, bem como de poder sentir, pensar e inventar (Dejours, 2004). Dessa forma, trabalhar não é somente uma atividade ou a produção de algo; é sim a transformação de si mesmo e uma possibilidade de realização (Dejours, 2004).

No entanto, a atividade produtiva, sobretudo a manual, é considerada uma prática sem inteligência, visto que, historicamente, o trabalho braçal é realizado "de modo geral, do pescoço para baixo e não do pescoço para cima" (Rose, 2007, p. 30); enquanto o trabalho especializado envolve atribuições de cognição e inteligência que conferem um lugar na ordem social às pessoas que o desenvolvem (Rose, 2007), conforme corrobora Costa (2008, p. 11):

Bater o ponto, vestir o uniforme, executar trabalhos essencialmente simples (como varrer ruas, cortar mato, retirar o barro que se acumula junto às guias), estar sujeito a repreensões mesmo sem motivo, transportar-se diariamente em cima da caçamba de caminhonetes ou caminhões em meio às ferramentas ou lixo, são as tarefas delineadoras do trabalho daqueles homens. Tarefas nas quais pudemos reconhecer ingredientes psicológicos e sociais profunda e fortemente marcados pela degradação e pelo servilismo. São atividades cronicamente reservadas a uma classe de homens proletarizados; homens que se tornam historicamente condenados ao rebaixamento social e político. 
Para tanto, essa dicotomia do trabalho é resultado de um longo processo histórico (Costa, 2004; Rose, 2007) e tem perpetuado um desprestígio social da atividade laboral realizada. Tal desprestígio se faz presente quando os trabalhadores são considerados desqualificados intelectualmente e vistos apenas como executores de um trabalho braçal e precário (Diniz, Carrieri \& Barros, 2013). Ademais, o desprestígio social acontece quando se ignora a presença do sujeito que se encontra ali presente, não necessariamente pela não percepção física da pessoa, mas por ignorá-la propositalmente (Ventura, 2011).

Esse contexto acarreta em rejeição social, estendida a seus familiares (Nascimento, Santos \& Pinho, 2017), sentimento de humilhação social e sofrimento psicológico ao serem tratados com desprezo, indiferença (Diniz et al., 2013; Lourenço, 2014), sendo que, muitas vezes, ocorrem agressões físicas e verbais por parte dos clientes, bem como falta de apoio dos superiores (Lourenço, 2014). Assim, as características do desprestígio também estão relacionadas à falta de reconhecimento organizacional, ao desgaste físico e psicológico que a ocupação profissional ocasiona (Ulmann, 2014) e aos riscos aos indivíduos, tanto de ordem física como psicológica (Diniz et al., 2013).

Coerente ao exposto, o conceito de invisibilidade pública emerge ao abordar o desaparecimento de um homem no meio de outros homens (Costa, 2004). A invisibilidade pública na atividade laboral é corroborada quando a pessoa veste o seu uniforme e utiliza suas ferramentas de trabalho (Costa, 2004). Nesse sentido, essas vestimentas e ferramentas conferem ao indivíduo muito mais do que o status de trabalhador braçal; elas lhe legam a invisibilidade pública (Costa, 2004, 2008). Para tanto, ao olhar da maioria das pessoas, os trabalhadores são seres invisíveis, sem nome e que, ao vestirem o uniforme de gari, não são reconhecidos nem mesmo pelos seus amigos. $\mathrm{O}$ sujeito não é ignorado ou rejeitado, mas sim, não é percebido, como se não estivesse presente.

A invisibilidade pública é um processo pelo qual o homem é tornado invisível por sua insignificância ou irrelevância social (Costa, 2004, 2008). Assim, a sociedade valoriza determinados tipos de trabalho em função da representatividade que possuem, sendo que algumas profissões, como médicos, engenheiros e advogados, historicamente reforçaram suas posições de prestígio produzindo práticas monopolistas que estabeleceram barreiras frente às demais profissões (Coelho, 1999). Por exemplo, a atividade de um médico é mais valorizada que outras, em função do status e pelo tempo que os profissionais dedicam à sua formação (Gallon, Bitencourt, Viana \& Antonello, 2016; Silva, Melo \& Vasconcelos, 2014).

Neste contexto, a atividade de um médico exemplificada pode ser considerada uma profissão liberal, que, originalmente do termo latino liberalis, "designava o indivíduo que, ademais de liberdade política, gozava de boa situação material, o que lhe permitia dedicar horas de lazer ao estudo" (Coelho, 1999, p. 21). De modo contrário, o ofício de um garçom não possui o mesmo prestígio (gallon et al., 2016), sendo considerado desqualificado intelectualmente por ser executor de um trabalho braçal e precário, conforme apontam Diniz et al. (2013).

Os estudos sobre o trabalho devem buscar um olhar contemporâneo diante de sua contribuição socioeconômica. Ademais, é importante entender o trabalho na perspectiva organizacional - processos de aprendizagem e resolução de problemas - e individual - criação de identidade e interação social para esses sujeitos (Rose, 2007). Consequentemente, o trabalho comum tem despertado interesse na academia e vem sendo estudado em diferentes ocupações, como manicures e pedicures (Gallon et al., 2016), garçons e garçonetes (Diniz et al., 2013), auxiliares de limpeza (Diogo, 2007), cabeleireiras (Rose, 2007), carpinteiros (Rose, 2007), doceiras (Dantas, 2014), catadores de lixo (Medeiros \& Macedo, 2006), garis (Costa, 2008) e agentes funerários (Nascimento et al., 2017).

Por todo exposto, a fim de caracterizar o trabalho comum (Rose, 2007), esta pesquisa utiliza o conceito de desprestígio social (Diniz et al., 2013), considerada uma desvalorização da ocupação profissional (Santos, 2015), tendo em vista que as características são construídas por uma parcela da sociedade, a qual, não necessariamente, condiz com a perspectiva das pessoas que exercem o trabalho comum. 


\section{Os sentidos do trabalho}

Além de fonte de sustento (Morin, 2001) e atividade autodeterminada, externa à relação dinheiro-mercadoria (Dourado, Holanda, Silva \& Bispo, 2009), o trabalho é também um meio para se relacionar com os outros, uma ocupação e uma forma de se sentir pertencente a uma comunidade (Morin, 2001). Assim, o trabalho tem diversos sentidos para os sujeitos, sendo do interesse dos pesquisadores investigar a temática em diferentes esferas organizacionais.

As primeiras pesquisas sobre sentidos do trabalho foram realizadas por Hackman e Oldham (1975), que buscaram relacionar o sentido do trabalho com a qualidade de vida (Tolfo $\&$ Piccinini, 2007). Esses autores reconheceram que um trabalho que possui sentido deve ser legítimo, útil e importante para o sujeito que o realiza, apresentando três características essenciais: possuir variedade nas tarefas, oferecer possibilidade de realizar algo com começo e fim demonstrando resultados e, ainda, oferecer retorno ao sujeito sobre seu desempenho (Hackman \& Oldham, 1975).

Para tanto, embasada nos estudos do grupo Meaning of Work International Research Team (MOW), Morin (2001) expõe suas reflexões sobre um trabalho com sentido, no qual suas proposições estão voltadas em constructos, como motivação e comprometimento. Nesse contexto, à medida que o sujeito encontra sentido no que realiza, suas ações para com seu trabalho e com a organização tornam-se mais comprometidas (Morin, 2001; Rohm \& Lopes, 2015). Morin (2001) investigou os sentidos do trabalho e do emprego em estudantes de Administração e administradores profissionais da França e Quebec. A pesquisa concluiu que, para os estudantes, o trabalho possui uma concepção positiva e vários são os fatores que os motivam a trabalhar, entre eles: contribuição social, sentimento de vínculo, fonte de realização, atualização do potencial, bem como ter um sentido. Para o grupo de administradores, o trabalho também possui uma visão positiva e tem sentido quando é feito de maneira eficiente, conduz a algum objetivo, beneficia outras pessoas, permite o aprendizado, a realização e exerce poder.

Nesse contexto, Morin (2001) ressalta que as características essenciais de um trabalho com sentido são compostas por dimensões que aludem envolvimento cognitivo e afetivo por parte daquele que o realiza. A finalidade da ação, a eficiência da atividade, a possibilidade de satisfação intrínseca e a garantia de segurança e autonomia são os pontos que conduzem o trabalhador a realizar um trabalho com sentido. Juntamente a isso, o fato de trabalhar é considerado moralmente aceitável, proporcionando o desenvolvimento de uma rotina diária, bem como a afiliação do trabalhador em um determinado grupo social.

Coerente a isso, as atividades diárias laborais, mesmo que sejam de um trabalho comum, sem prestígio social, como o da garçonete, têm grande valor para as pessoas que o exercem, pois envolvem um misto de utilidade e de cuidados a outros (Rose, 2007) gerando tanto valor pessoal (Dourado et al., 2009) quanto para comunidade pertencente (Nascimento et al., 2017).

Esta valorização pode ser percebida no estudo realizado sobre o sentido do trabalho com agente funerário. Os achados deste estudo apontam que na dimensão organizacional, os agentes funerários encontram sentido principalmente no reconhecimento dos seus serviços pelos clientes e em relação à sua utilidade para a empresa. $\mathrm{Na}$ dimensão individual, percebem sentido no que se refere à valorização, desenvolvimento, independência, sobrevivência e alienação - essa última refere-se quando o profissional desconhece o objetivo do seu trabalho e não sabe o porquê de estar sendo realizado - (Oliveira, Piccinini, Fontoura \& Schweig, 2004; Tolfo \& Piccinini, 2007). Contudo, a dimensão social apresentou mais pontos de um trabalho sem sentido diante da valorização do seu ofício nas relações interpessoais do agente funerário. Assim, os entrevistados relatam que sua ocupação é alvo de curiosidade e perplexidade por parte de sua família e de brincadeiras por parte dos amigos, sendo alvo de preconceito pela sociedade (Nascimento et al., 2017). 
O trabalho também pode ser entendido e vivenciado como sofrimento, esforço doloroso, tortura e fonte de alienação (Zanelli et al., 2010). Tal compreensão vincula o labor à exploração e deterioração da qualidade vida que possui, quando o sujeito despende esforço físico e psíquico com significados negativos ou pouco relevantes (Nascimento et al., 2017; Silva \& Tolfo, 2012). Por isso, pode-se dizer que o trabalho não é, por si só, fator de adoecimento, mas determinadas condições e seus contextos podem causar prazer e desgaste no indivíduo, que poderão interferir na qualidade de vida dos trabalhadores (Glanzner, Olschowsky \& Kantorski, 2011).

Assim, caso o homem perceba o trabalho somente como algo necessário à sua sobrevivência e aquisições, entendendo como atividade obrigatória, deixa de compreender este trabalho como atividade de integração individual e social (Tolfo \& Piccinini, 2007). Torna-se, portanto, meramente alienado, um produtor e consumidor de capital que deixa de buscar sua identidade nas atividades que executa e, consequentemente, deixa de atribuir sentido ao que faz (Tolfo \& Piccinini, 2007).

Deste modo, compreende-se que o trabalho é uma atividade que agrega valor e possui sentido à medida que proporciona prazer e sentimento de realização ao executá-lo, permitindo exercer seus talentos e competências (Morin, 2001), realizar-se e aumentar a autonomia (Morin, 2001; Tolfo \& Piccinini, 2007). Um trabalho que tem sentido é influenciado pela variedade das tarefas (Hackman \& Oldham, 1975; Morin et al., 2007); é promotor dos laços sociais, fonte de realização; e mostra que o sujeito é capaz de contribuir e ser útil para a sociedade (Bitencourt, Gallon, Batista \& Piccinini, 2011; Hackman \& Oldham, 1975; MOW, 1987; Morin, 2001; Piccinini, Oliveira, Fontoura \& Schweig, 2005; Rose, 2007; Tolfo \& Piccinini, 2007), possibilitando construção da identidade pessoal e social do indivíduo (Rose, 2007; Tolfo \& Piccinini, 2007).

\section{Procedimentos metodológicos}

Esta pesquisa tem abordagem qualitativa por detalhar um fenômeno social que aborda a relação de configuração, estrutura, mudanças e relacionamentos do elemento em questão com outros dados (Godoy, 2005). Adotando o enfoque exploratório e descritivo, as pesquisadoras estavam abertas para as descobertas do campo (Godoy, 1995) a fim de analisar a percepção sobre os sentidos do trabalho para pessoas que exercem um trabalho comum, frente à invisibilidade pública e ao desprestígio social da atividade exercida.

Para tanto, a coleta dos dados foi realizada por meio de entrevista com base em um roteiro semiestruturado, desenhado a partir do referencial teórico exposto anteriormente. O roteiro tinha 31 questões divididas em três blocos: (1) perfil do entrevistado e características do emprego; (2) trabalho; e (3) sentidos do trabalho. O instrumento de coleta de dados passou por um pré-teste e foi adaptado ao perfil dos entrevistados, proporcionando assim melhor entendimento aos participantes da pesquisa. $O$ instrumento contemplou perguntas sobre relações sociais e familiares, valorização do trabalho que desenvolvem, aspectos financeiros e perspectivas futuras. Foram entrevistados 32 trabalhadores que exerciam diferentes ocupações com vínculo empregatício e autônomos e sem distinção de sexo e idade, em uma cidade do Norte do estado do Rio Grande do Sul. Optou-se por trabalhadores com baixa escolaridade - até ensino fundamental completo - em virtude de que os trabalhos comuns são caracterizados pela baixa escolaridade, salário e renda (Rose, 2007), visto que o conhecimento formal é dispensável, não sendo um requisito para exercer o trabalho.

Ao total, foram entrevistados 18 homens e 14 mulheres: entre 20 a 59 anos; pessoas solteiras, casadas, divorciadas ou com união estável; e escolaridade de analfabeto até a oitava série completa. As ocupações dos entrevistados eram de auxiliar de serviços gerais, auxiliar de limpeza, babá, cabeleireira, carpinteiro, coletor de lixo, encarregado de almoxarifado, frentista, garçom, gari, manicure, operador de grua, pedreiro, pintor, porteiro, servente de pedreiro, vigilante e zeladora (Quadro 1). 
Quadro 1: Perfil dos entrevistados

\begin{tabular}{|c|c|c|c|c|c|c|}
\hline Entrevistado & Sexo & Idade & Ocupação Profissional & Escolaridade & Estado Civil & $\begin{array}{c}\text { Regime de } \\
\text { Trabalho }\end{array}$ \\
\hline E1 & Feminino & 44 anos & Auxiliar de serviços gerais & Analfabeta & União estável & Celetista \\
\hline E2 & Feminino & 25 anos & Auxiliar de serviços gerais & 6 ${ }^{\mathrm{a}}$ série & União estável & Celetista \\
\hline E3 & Masculino & 29 anos & Operador de grua & 8 série & Casado & Celetista \\
\hline E4 & Masculino & 25 anos & Pedreiro & 8 série & Casado & Celetista \\
\hline E5 & Masculino & 21 anos & Servente de pedreiro & 8 a série & Solteiro & Celetista \\
\hline E6 & Masculino & 45 anos & Servente de pedreiro & $4^{\mathrm{a}}$ série & Casado & Celetista \\
\hline E7 & Masculino & 23 anos & Encarregado de almoxarifado & $8^{\mathrm{a}}$ série & Casado & Celetista \\
\hline E8 & Feminino & 32 anos & Serviços gerais & 8 série & Solteira & Celetista \\
\hline E9 & Feminino & 49 anos & Auxiliar de limpeza & $5^{\mathrm{a}}$ série & Casada & Celetista \\
\hline E10 & Feminino & 27 anos & Serviços gerais & 8 série & Solteira & Celetista \\
\hline E11 & Masculino & 59 anos & Vigilante & 8a série & Casado & Celetista \\
\hline E12 & Masculino & 42 anos & Porteiro & 8 a série & Casado & Celetista \\
\hline E13 & Masculino & 45 anos & Pedreiro & $6^{\mathrm{a}}$ série & Casado & Celetista \\
\hline E14 & Masculino & 24 anos & Pintor & $4^{\mathrm{a}}$ série & Casado & Celetista \\
\hline E15 & Masculino & 47 anos & Frentista & $5^{\mathrm{a}}$ série & Casado & Celetista \\
\hline E16 & Feminino & 40 anos & Auxiliar de limpeza & $5^{\mathrm{a}}$ série & Casada & Celetista \\
\hline E17 & Feminino & 57 anos & Babá & $7^{\mathrm{a}}$ série & Casada & Celetista \\
\hline E18 & Masculino & 53 anos & Vigilante & 7- série & Solteiro & Celetista \\
\hline E19 & Feminino & 53 anos & Manicure & 8a série & Solteira & Autônoma \\
\hline E20 & Feminino & 42 anos & Cabeleireira & $4^{a}$ série & Casada & Autônoma \\
\hline E21 & Feminino & 23 anos & Auxiliar de limpeza & 8 série & Casada & Celetista \\
\hline E22 & Masculino & 43 anos & Coletor de lixo & 6⿳亠丷厂 série & Casado & Celetista \\
\hline E23 & Feminino & 44 anos & Manicure & $5^{\underline{a}}$ série & Casada & Autônoma \\
\hline E24 & Feminino & 20 anos & Auxiliar de limpeza & 8a série & União estável & Celetista \\
\hline E25 & Masculino & 53 anos & Carpinteiro & $2^{\mathrm{a}}$ série & Solteiro & Celetista \\
\hline E26 & Feminino & 35 anos & Gari & 6⿳亠口了 série & Separada & Celetista \\
\hline E27 & Masculino & 37 anos & Frentista & $5^{\mathrm{a}}$ série & Casado & Celetista \\
\hline E28 & Feminino & 38 anos & Zeladora & $5^{\mathrm{a}}$ série & Casada & Celetista \\
\hline E29 & Masculino & 28 anos & Garçom & 8 a série & Casado & Celetista \\
\hline E30 & Masculino & 24 anos & Garçom & 8 a série & Solteiro & Celetista \\
\hline E31 & Masculino & 55 anos & Coletor de lixo & 4⿳亠丷a série & Solteiro & Celetista \\
\hline E32 & Masculino & 25 anos & Frentista & 8르 série & Casado & Celetista \\
\hline
\end{tabular}

Fonte: Elaborado pelas autoras (2018).

Os entrevistados foram escolhidos através de contatos diretos na rua ou estabelecimentos, como com garis e auxiliares de limpeza, e através de redes sociais, em que os trabalhadores eram sugeridos para as entrevistas. Após verificar se as pessoas indicadas atendiam o perfil definido, escolheram-se os trabalhadores que tivessem diferentes ocupações e aos quais as pesquisadoras tinham fácil acesso. Alguns entrevistados foram abordados em seu ambiente de trabalho; outros, enquanto estavam almoçando, durante seu intervalo; e alguns, em momentos de lazer. Houve também aqueles em que as pesquisadoras encontravam realizando seu trabalho, mas como não podiam ser entrevistados naquele momento, informavam o número do telefone para contato posterior. Assim, algumas entrevistas também foram realizadas em pontos estratégicos da cidade, conforme disponibilidade dos trabalhadores, fora do expediente.

Procurou-se entrevistar trabalhadores que não pertencessem ao convívio das pesquisadoras, com o intuito de que eles ficassem à vontade em suas colocações. As entrevistas tiveram duração de 50 minutos, em média; aconteceram nos meses de junho e julho de 2017; e foram realizadas individualmente. No entanto, algumas vezes, houve interrupção por parte de colegas de trabalho dos entrevistados ou até mesmo por necessidade de atender ao telefone. 
As entrevistas foram gravadas com gravador de áudio e transcritas posteriormente. Após a explicação do objetivo do estudo, os trabalhadores assinaram um termo de consentimento livre e esclarecido concedendo a autorização para realizar as entrevistas com uso exclusivo em pesquisa científica. As entrevistas só iniciaram após a assinatura do termo e quando os trabalhadores estavam cientes da pesquisa, sem dúvidas ou outras questões pertinentes ao estudo.

Um fato que chamou a atenção das pesquisadoras durante as entrevistas foi o receio ou vergonha inicial dos trabalhadores em ceder suas respostas. No início, as respostas dos entrevistados eram mais objetivas, porém, com o desenrolar da conversa, observou-se maior interação entre pesquisador e entrevistado. Assim, os trabalhadores ficaram mais à vontade, traziam exemplos de vivências do trabalho e a conversa fluía naturalmente.

A análise dos dados foi realizada por meio da técnica de análise de conteúdo, que consiste em descobrir os núcleos de sentido que compõem uma comunicação, através de três etapas: (i) pré-análise; (ii) exploração do material; e (iii) tratamento, inferência e interpretação dos resultados (Bardin, 2009). Para a organização das categorias, utilizou-se o software Max-Qda versão 2007, que não automatiza e nem executa a análise dos dados (Flick, 2002), sendo responsabilidade das pesquisadoras realizarem a categorização das informações.

O processo de codificação resultou em 20 códigos, que incluíram as categorias iniciais estruturadas de acordo com o roteiro de entrevistas, categorizando 636 segmentos de dados. A partir dessa estruturação, realizou-se uma análise mais aprofundada que buscou encontrar outros dados que estavam ocultos e, também, para melhor estruturação das categorias finais. A partir disso, cinco categorias de análise foram encontradas (trabalho comum, relações sociais e familiares, valorização da ocupação profissional, importância financeira e visão de futuro), possibilitando a organização do dicionário (Bardin, 2009), ou seja, uma compilação de termos com suas respectivas ideias-chave, que resumem os sentidos do trabalho para os indivíduos que exercem trabalhos comuns (Quadro 2).

Quadro 2: Categorias finais e ideias chave das categorias

\begin{tabular}{|c|c|}
\hline Categorias & Ideias-chave \\
\hline Relações sociais e familiares & $\begin{array}{l}\text { - Família é o eixo principal. } \\
\text { - Sustento e sobrevivência familiar e individual. } \\
\text { - Espaço para dialogar. } \\
\text { - Recomendação da ocupação profissional. } \\
\text { - Pertencimento. } \\
\text { - Companheirismo e apoio. }\end{array}$ \\
\hline Valorização da ocupação profissional & $\begin{array}{l}\text { - Utilidade social. } \\
\text { - Sentimento de dever cumprido. } \\
\text { - Desenvolver autonomia e responsabilidades. } \\
\text { - Dignifica a pessoa. } \\
\text { - Essencial na vida. } \\
\text { - Gostar do que se faz. } \\
\text { - Tornam a vida das pessoas mais fácil. }\end{array}$ \\
\hline Importância financeira & $\begin{array}{l}\text { - Fundamental para sobreviver. } \\
\text { - Aquisição de bens materiais. } \\
\text { - Pagar as contas do mês. } \\
\text { - Independência. } \\
\text { - Meio de receber um salário. } \\
\text { - Não deixariam de trabalhar se tivessem bastante dinheiro. }\end{array}$ \\
\hline Visão de futuro & $\begin{array}{l}\text { - Contemplar sonhos, projetos e desejos. } \\
\text { - Continuar no emprego atual. } \\
\text { - Continuar trabalhando. } \\
\text { - Aposentadoria. } \\
\text { - Empreender. }\end{array}$ \\
\hline Trabalho comum & $\begin{array}{l}\text { - Eixo essencial na vida. } \\
\text { - Falta opção. } \\
\text { - Baixa escolaridade. } \\
\text { - Autonomia. }\end{array}$ \\
\hline
\end{tabular}

Fonte: Elaborado pelas autoras (2018). 
A análise e a interpretação das informações de acordo com a literatura proposta nesta pesquisa são expostas na próxima seção.

\section{Análise dos resultados}

Nesta seção, é apresentada a análise das entrevistas a partir das cinco categorias elencadas (relações sociais e familiares, valorização da ocupação profissional, importância financeira, visão de futuro e trabalho comum), com base nas principais ideias-chave que compõe cada categoria.

A primeira categoria analisada descreve a percepção dos entrevistados quanto às relações sociais e familiares. Os entrevistados relatam a importância da família, mais especificamente dos filhos, colocando-a em primeiro lugar, seguida pelo trabalho. É através do trabalho que os trabalhadores têm a oportunidade de construir sua identidade, interagir socialmente, encontrar um propósito e desafios, adquirir status e obter renda (Zanelli et al., 2010) para o sustento da família.

Dessa forma, o trabalho apresenta um papel central na vida dos entrevistados, ao passo que até mesmo no momento em que chegam em casa ele é citado nas conversas com seus familiares. Eles relatam sobre como foi seu dia, desabafam sobre aspectos que não foram tão positivos no trabalho, como também compartilham as conquistas diárias, como pode ser percebido: "eu falo com a família sobre o trabalho, falo sobre a firma, que é uma firma boa de trabalhar, coisa assim. A gente fala só de coisas boas, coisa ruim não tem" (E13, 45 anos, pedreiro). No mesmo sentido, outro entrevistado menciona que "converso mais com a esposa, quando acontece alguma coisa, eu chego e falo com ela, desabafar um pouco" (E12, 42 anos, porteiro), ou seja, eles encontram espaço na família para dialogar sobre seu trabalho.

Outro ponto que se destacou nas narrativas foi a convivência com os colegas de trabalho, o que deixa claro o sentimento de pertencimento adquirido nas relações diárias. As experiências vividas no trabalho apresentam uma positividade, considerando que no trabalho as pessoas podem desenvolver laços de afeição duráveis, ou seja, na dimensão organizacional, o trabalho aparece como uma oportunidade que a pessoa tem de se relacionar com outras pessoas (Morin, 2001). As relações sociais podem ser percebidas ao relatarem que "até mesmo porque saindo de casa a gente convive mais com as pessoas do trabalho do que com a família da gente, né. Então, eu vejo meu trabalho como minha segunda família" (E2, 25 anos, serviços gerais). Outro relata que "fico feliz de acordar e vim trabalhar, encontrar os colegas, a gente conversa bastante" (E27, 37 anos, frentista). Dessa forma, o trabalho proporciona o sentimento de pertencimento, fazendo com que os trabalhadores se sintam bem com as relações advindas do trabalho.

Este fato se torna ainda mais evidente ao serem questionados do que mais sentiriam falta no caso de perderem o trabalho, e a maioria dos entrevistados não hesitaria em colocar os colegas de trabalho em primeiro lugar, reforçando o sentimento de vinculação e pertença, como se pode observar quando é mencionado que "sentiria falta da galera em geral, todo mundo gente boa, porque tipo, a questão financeira iria sentir falta também, mas isso tem uma válvula de escape para ti correr atrás e repor o que está faltando" (E30, 24 anos, garçom). Outro trabalhador reafirma o sentimento afirmando que também "sentiria mais falta das amizades e dos companheiros. Vou dar um exemplo, ficamos três dias e meio trabalhando junto, nós éramos companheiros, o que um precisa, liga para o outro, nós éramos assim, sempre foi assim" (E12, 42 anos, porteiro). O apoio recebido dos colegas de trabalho reforça os relacionamentos organizacionais e contribui de forma positiva com o sentimento de vínculo.

Como exposto, os entrevistados consideram a importância dos relacionamentos no trabalho, uma vez que passam a maior parte do seu dia convivendo com seus colegas, conforme relata a E20 (42 anos, cabeleireira): "eu sentiria falta da convivência também né, porque a gente conversa faz amizades, não seria só do dinheiro, mas dessa convivência, dessas amizades". Este sentimento de coleguismo, 
de reciprocidade aparece fortemente associado ao gosto pelo trabalho. Assim, o relacionamento com as pessoas, o sentimento de vinculação, de pertença e o fato de ter algo a fazer para evitar o tédio no trabalho possuem um lugar de destaque no meio social (Morin, 2001).

Na segunda categoria buscou-se compreender a valorização da ocupação profissional pelo sentido que os entrevistados encontram no trabalho, ao entender suas histórias e seu cotidiano, suas realizações e dificuldades proporcionadas pelo trabalho considerado de baixo prestígio social.

Ao serem questionados sobre qual o sentido do trabalho, destacou-se a utilidade; os entrevistados expressaram que o trabalho possui sentido ao passo que se torna útil para as pessoas, pois "muitos ainda enxergam o trabalho da gente, a gente deixa tudo limpinho para ajudar, porque é ruim tu chegar num lugar que o ambiente está sujo" (E8, 32 anos, auxiliar de serviços gerais) e, dessa forma, o trabalhador é capaz de mostrar a utilidade do seu trabalho. Outros relatam que o sentido do trabalho encontra-se em: "ocupar tua mente eu acho, fazendo alguma coisa útil não só para ti, mas pra mais pessoas e sendo remunerado por isso" (E30, 24 anos, garçom), assim como: "trabalhar te faz bem, uma pessoa que fica inútil, sem fazer nada, acredito que nem se sinta bem, não tem prazer para nada, acho que meu trabalho ajuda na questão, assim, interior da pessoa, o trabalho dignifica a pessoa, ela é bem vista" (E20, 42 anos, cabeleireira). Sendo assim, o trabalho, além de ser útil, proporciona o sentimento de dignidade para os trabalhadores que o realizam.

Nos relatos, o trabalho apresenta sentido na dimensão social em relação à sua utilidade (Nascimento et al., 2017), pois percebem sua contribuição à sociedade e demonstraram que se sentem bem em poder fazer com que a vida das pessoas direta ou indiretamente envolvidas se torne mais fácil e agradável, como consequência do seu trabalho, pois "nisso de limpeza tem sentimento, porque a gente vê tudo limpo. As pessoas tão satisfeitas, aí elas comentam que está limpinho e tu fica melhor ainda" (E10, 27 anos, auxiliar de serviços gerais), e isso proporciona o sentimento de dever cumprido.

Assim, os entrevistados demonstraram que suas atividades são úteis à sociedade, por mais que esta nem sempre os perceba como seres humanos, e sim apenas como trabalhadores invisíveis, imperceptíveis, com baixo prestígio social e que se submetem a atividades que outros trabalhadores não se submeteriam. Neste contexto, se torna nítido a rejeição social (Nascimento et al., 2017), sentimento de humilhação social e sofrimento psicológico ao serem tratados com desprezo, indiferença (Diniz et al., 2013; Lourenço, 2014), até mesmo porque "eles não davam assistência nenhuma pra gente: tipo se tu molhava teus pé, tu ia ficar o dia inteiro molhada, se tu se molhasse, não tinha um tênis, nada, nada, nada" (E8, 32 anos, serviços gerais). O desprezo e indiferença narrados interferem na forma como projetam o futuro de seus filhos.

Nas narrativas, o sofrimento e o desejo que seus filhos não passem pela mesma situação ficam aparentes, pois "não recomendaria de jeito nenhum, porque a gente quer o melhor pros filhos, não vai querer que passem o que a gente passa, a gente sofre, não é fácil esse serviço" (E8, 32 anos, serviços gerais), mas se submetem pois percebem o trabalho como um amparo contra a pobreza, visto que, na sua ausência, as implicações podem ser graves (Rose, 2007).

A terceira categoria aborda a questão financeira. A maioria dos entrevistados demonstra gostar muito do trabalho que fazem, porém, sempre lembrando a necessidade financeira, que os obriga a se manterem ativos no mercado de trabalho, pois "se tu não tem o dinheiro, tu não pode fazer nada, desde comprar um alimento, se não tem tu tem que fica sem" (E6, 45 anos, servente de pedreiro). A questão financeira, proporcionada pelo trabalho, diversas vezes foi comentada pelos entrevistados, demonstrando sua importância. Esse achado corrobora com estudos anteriores (Piccinini et al., 2005; Tolfo \& Piccinini, 2007) nos quais destaca-se que o fator financeiro, por si só, não traz sentido para o trabalho, mas sim quando ele é percebido como algo complementar na vida do indivíduo.

Observa-se que, para alguns, a finalidade do trabalho é a renda, enquanto as demais características seriam complementares. Para outros, no entanto, a recompensa financeira é um complemento, pois a importância do trabalho está em gostar daquilo que faz, está na independência, 
no sentimento de pertencimento, que ele proporciona, como relata E9 (49 anos, auxiliar de limpeza): "me sinto bem trabalhando. Eu trabalho porque eu gosto e outra porque eu preciso".

Todos os respondentes manifestaram a mesma percepção, de que não conseguiriam viver sem trabalhar, mesmo se tivessem bastante dinheiro para viver confortavelmente o resto da vida, conforme o relato da E16 (40 anos, auxiliar de limpeza):

Bastante dinheiro? Nunca pensei nisso, eu não sei, mas alguma coisa tu tem que fazer, sempre vai ter que fazer, não tem como só ficar deitada, não existe. Eu não me imagino só deitada, só sentada, sem ter o que fazer. É uma coisa boa para ti, tipo eu tirei férias, meu Deus! Eu não aguentava mais. Eu queria voltar a trabalhar. Eu acho que se eu ficasse mais um pouco, eu ia entrar em depressão.

Estes achados corroboram com alguns estudos já realizados anteriormente (Morin, 2001; Teixeira \& Lorenzzon, 2016), em que as pessoas pesquisadas disseram que mesmo que fossem abastados financeiramente, continuariam trabalhando. A importância do trabalho também é reforçada, ao passo que proporciona o sentimento de independência, conforme depoimento do E1 (44 anos, serviços gerais):

É o meio que a gente tem de ser independente né, querer fazer o que tu quer, né, tu ter o direito de ir e vir, não pedir, ficar esperando pelo marido, chegar no final do mês, tem que estar contando para ele o que tu vai fazer o que tu não vai fazer, o que tu tem para pagar, entende? Assim, a gente é independente, entende?

Dessa forma, o salário possibilita que os trabalhadores entrevistados sejam mais independentes, e que os compromissos financeiros mensais sejam cumpridos: "nós dois estávamos há pouco tempo sem serviço, eu estava trabalhando de faxina e não era todo dia, só de vez em quando e imagina, pagar aluguel, água, luz essas coisas assim, e não ter um trabalho fixo, né?" (E2, 25 anos, auxiliar de serviços gerais).

Já na quarta categoria, que se refere à visão de futuro, fica evidente que o trabalho proporciona aos entrevistados oportunidades de realizações pessoais, as quais sem o trabalho não seriam possíveis. O interesse por trabalhar está vinculado com as oportunidades proporcionadas pelo trabalho, como viver de acordo com os valores pessoais, ter a oportunidade para realização de ambições, vencer desafios ou perseguir ideias (Morin, 2001), como pode ser visto:

O trabalho, na realidade na minha vida assim é o que mantém a possibilidade da gente sonhar, sabe? Em ter uma condição de vida melhor, de ter um carro melhor, de dar uma oportunidade para a família, de um passeio, né? Através deste pensamento, assim que, tipo, a gente vem trabalhar, tu sempre está focando no dia de amanhã (E3, 29 anos, operador de grua).

Desta forma, os entrevistados demonstram aspectos que permeiam as necessidades financeiras, o desejo de melhorar de vida, sua projeção de futuro, a possibilidade de adquirir coisas materiais, ter o próprio negócio e proporcionar melhores condições de bem-estar para a família.

Nesta perspectiva de futuro, cabe ressaltar que cada trabalhador, ao exercer sua atividade, possui um objetivo final e um sentido atribuído àquilo que realiza (Tolfo \& Piccinini, 2007), e o sentido que o trabalho possui é construído em um determinado contexto social, econômico e histórico. Os trabalhadores entrevistados dizem encontrar sentido ao exercerem sua autonomia, que demonstra como o trabalho possibilita aos entrevistados contemplar seus sonhos, projetos, desejos e liberdade de escolhas.

Por fim, foram abordados pontos que caracterizam o trabalho comum e, dentre eles, a falta de escolaridade ganha destaque. Ao contrário de um trabalho especializado, que envolve atribuições 
de cognição e inteligência, conferindo um lugar de prestígio na ordem social às pessoas que o desenvolvem (Rose, 2007), as profissões exercidas pelos entrevistados não exigem uma especialização.

Os entrevistados ressaltam que a falta de escolaridade torna-se um fator que os impossibilita de buscar outras ocupações e acabam se conformando com ocupações profissionais que não exigem qualificações, conforme relatado pelo E9 (49 anos, serviços gerais): "escolhi trabalhar nesse ramo, para te dizer bem a verdade, por falta de estudo". Quando o E9 (49 anos, serviços gerais) relata que escolheu essa ocupação, entende-se que isso não foi uma escolha e sim a única alternativa frente à falta de opções, situação característica de pessoas que desenvolvem um trabalho comum; com baixa escolaridade; ou que estão à margem da sociedade. Isso também fica evidente no relato, como: "não, não estudei, então, geralmente quem trabalha nessas [profissões] não tem opção de outra profissão, entende?" (E1, 44 anos, auxiliar de serviços gerais). Assim, os entrevistados encontram uma justificativa para a escolha de suas profissões, em que a baixa escolaridade é a sua principal causa, e o conhecimento formal torna-se indispensável, não sendo uma exigência para exercer o trabalho (Rose, 2007).

Importante destacar que a necessidade econômica familiar impunha a busca por trabalho muito cedo. Alguns entrevistados narraram que iniciaram sua jornada de trabalho ainda muito novos, alguns ainda na infância, conforme o relato do E15 (47 anos, frentista): "lá com 15 anos eu trabalhava o dia inteiro porque minha família precisava de mim, aí precisava trabalhar o dia inteiro pra ajudar no sustento". A alienação ao trabalho mostrada na fala do entrevistado é coerente com a perspectiva de alienação do trabalho abordada por Tolfo e Piccinini (2007) ao relatar que o trabalho aparece como uma necessidade econômica familiar, em que o trabalhador percebe o trabalho apenas como uma forma de sobrevivência, não conseguindo identificar outros sentidos ao seu trabalho, nem associar as atividades exercidas com o sentimento de desenvolvimento e evolução pessoal e social, bem como não sabe ao certo por que o está fazendo (Tolfo \& Piccinini, 2007; Oliveira et al., 2004).

Apesar da alienação ao trabalho, por um lado, e garantir o sustento, por outro as consequências do trabalho infantil acarretam em sentimento de humilhação social e sofrimento psicológico ao serem tratados com desprezo, indiferença (Diniz et al., 2013; Lourenço, 2014), sendo que, muitas vezes, ocorrem agressões físicas e verbais, bem como a falta de apoio dos superiores (Lourenço, 2014), conforme narrado pela E1 (44 anos, serviços gerais):

O trabalho que eu não me sentia bem era lá no começo quando eu comecei, quando a gente ia trabalhar de babá, entende. A gente era nova, a gente passou por muitas dificuldades no serviço, o fato de a gente querer trabalhar para ajudar em casa, a gente passou por muitas assim, e bastante dificuldade, com os patrões, né. Quando a pessoa é uma criança não sabe o que está fazendo, os patrões não entendem, eles te colocam de castigo, eles te judiam, te ameaçam. E eu era [castigada].

Deste modo, o trabalho comum é retratado pelos entrevistados em função do desprezo, humilhação e invisibilidade que são atrelados ao status da ocupação profissional (Costa, 2004; Diniz et al., 2013). Alguns trabalhadores são tratados com desrespeito e indiferença, porque "as pessoas passam e xingam por que ela está ali limpando e a pessoa não quer sair do lugar, sabe? Daí é esse o problema, é falta de respeito, né!" (E26, 35 anos, gari). Apesar dos entrevistados valorizarem o trabalho que desenvolvem e perceberem uma contribuição para a sociedade, a insatisfação, de acordo com os depoimentos, é frequentemente percebida pelo não reconhecimento do esforço executado e pela falta de prestígio social.

A partir dos relatos, identificou-se os sentidos do trabalho, relacionados às principais formas como os trabalhadores entrevistados compreendem suas experiências nas organizações (Vilas Boas \& Morin, 2014). Os sentidos relatados foram: estar bem consigo mesmo; gostar daquilo que faz; trabalhar com vontade e alegria; entender que o trabalho engrandece e faz bem; ter incentivo para 
melhorar seu trabalho; ter respeito, valorização; tirar proveito do trabalho e aprender coisas novas (Nascimento et al., 2017); obter reconhecimento (Dourado et al., 2009; Nascimento et al., 2017); ter horários flexíveis; e ser feliz. Na pesquisa de Morin et al. (2007), esses sentidos são classificados em uma dimensão individual em que a identificação e a satisfação pessoal no trabalho proporcionam sentido quando a pessoa que exerce o trabalho sente prazer, percebe contribuição como única e criativa, gosta do que faz e dá a sensação de independência financeira e psicológica (Morin et al., 2007).

Outros sentidos foram identificados, como o fato de manter o trabalhador ocupado o tempo inteiro (Nascimento et al., 2017). Isso sugere que o trabalho desempenhado tenha utilidade, e é classificado por Morin et al. (2007) em uma dimensão organizacional. Já os sentidos do trabalho em: proporcionar o desenvolvimento de relações sociais (Morin et al., 2007; Nascimento et al., 2017); ter espírito de equipe; e ajudar os outros (Nascimento et al., 2017) são classificados como dimensão social por Morin et al. (2007). Ao passo que se encontra sentido através da contribuição social, o trabalhador contribui para a sociedade e seu trabalho é considerado ético e aceitável (Morin et al., 2007).

Os sentidos do trabalho identificados nos relatos dos entrevistados também são descritos por outros autores, ainda que em contextos e ocupações profissionais diferentes (Morin et al., 2007). Contudo, foi possível identificar sentidos do trabalho no grupo de trabalhadores entrevistados, deixando claro que o trabalho não é somente uma fonte de renda, mas também de realização pessoal e profissional.

\section{Considerações finais}

O trabalho tem sido visto não somente como forma de obter renda e de suprir necessidades de subsistência, mas também como uma atividade que proporciona realização pessoal, reconhecimento social, desenvolvimento de laços sociais e construção de identidade do sujeito (Bastos, Pinho \& Costa, 1995; Bitencourt et al., 2011; Hackman \& Oldham, 1975; Morin, 2001; MOW, 1987; Piccinini et al., 2005; Rose, 2007; Tolfo \& Piccinini, 2007).

Para tanto, essa pesquisa buscou analisar a percepção sobre os sentidos do trabalho para pessoas que exercem um trabalho comum frente à invisibilidade pública e ao desprestígio social da atividade exercida. Cabe ressaltar que, a invisibilidade pública na atividade laboral é corroborada quando a pessoa veste o seu uniforme e utiliza suas ferramentas de trabalho (Costa, 2004), sendo um processo no qual o homem é tornado invisível por sua insignificância ou irrelevância social (Costa, 2004, 2008). O trabalhador que exerce um trabalho comum não deixa de existir socialmente, mas ele simplesmente não é percebido no momento em que executa seu trabalho, sendo ignorado pela sociedade. Aos olhos do trabalhador, seu trabalho possui utilidade para sociedade e fonte de sustento para sua família.

Frente a isso, o trabalho apresentou-se como central na vida dos trabalhadores, estando relacionado à: sobrevivência (Morin et al., 2007); inserção social (Bitencourt et al., 2011); e ao prazer em realizar as atividades que lhes são atribuídas (Glanzner et al., 2011). Evidenciou-se, também, que o trabalho é realizado com dignidade e os trabalhadores compreendem que aquilo que fazem tem uma finalidade e um valor para a sociedade (Morin, 2001; Rose, 2007; Tolfo \& Piccinini, 2007). Esses achados mostram que a percepção de inferioridade é atribuída pelos outros trabalhadores que não exercem as profissões aqui pesquisadas. Assim, o trabalhador especializado confere um rebaixamento social às pessoas que desenvolvem o trabalho comum (Costa, 2008; Rose, 2007).

Esse estudo possibilitou conhecer o contexto do trabalho comum, que está atrelado à invisibilidade pública e ao desprestígio social da atividade exercida, mas que tem importante 
contribuição para a sociedade. No âmbito teórico, a pesquisa visa contribuir com investigação dos sentidos do trabalho de diferentes ocupações profissionais e sociais, principalmente no Brasil, onde a desigualdade social é tão marcante (Morin et al., 2007).

$\mathrm{Na}$ esfera prática, a pesquisa fornece subsídios para a valorização do trabalhador a fim de entender o que traz sentido a esses trabalhadores, reconhecendo a importância do trabalho desenvolvido por esses sujeitos. Assim, o trabalho é uma importante esfera da vida, sendo elemento crítico na definição da identidade dos indivíduos (Bastos et al., 1995). Os motivos associados ao fato de trabalhar produzem sensações de ter um trabalho interessante e autorrealizador ao mesmo tempo em que apresenta uma função econômica, com rendimentos e ganhos (Bastos et al., 1995). A atribuição de sentido ao trabalho para os empregados acarreta em maior engajamento com a empresa, bem como na minimização de adoecimentos causados devido ao trabalho e consequentemente, na rotatividade e absenteísmo organizacional.

Pode-se mencionar como limitação do estudo a dificuldade dos trabalhadores em compreenderem o que estava sendo questionado. Isso se percebeu no decorrer das entrevistas, quando os trabalhadores solicitavam para repetir a pergunta e explicar com outras palavras. Em outros momentos, as respostas eram idênticas às relatadas em questões anteriores ou não respondiam de fato a questão. Na percepção das autoras, isso ocorreu em função de os entrevistados não estarem acostumados a refletir sobre o seu trabalho e o sentido que esse tem na vida deles, assim como quando os trabalhadores ficavam em silêncio, ou não se manifestavam em relação ao seu contexto de trabalho, era entendido como insegurança, medo de estar errado ou até mesmo de não querer falar sobre o local onde desenvolvem suas atividades.

Para tanto, essa pesquisa incita o desenvolvimento de novos estudos que permitam comparar os sentidos do trabalho em grupos de diferentes níveis de escolaridade, renda e ocupações a fim de que os resultados possibilitem emergir novos construtos que mostrem as diferenças e semelhanças do sentido do trabalho para os diferentes trabalhadores. Também é válido compreender esse contexto em diferentes países, visto as peculiaridades sociais de cada cultura. E, por fim, ressaltase a carência de pesquisas em relação à exigência do conhecimento formal frente aos diferentes saberes envolvidos na realização do trabalho, fomentando discussões sobre a elitização do conhecimento em diferentes profissões e, consequentemente, a visibilidade pública e o prestígio social do trabalho na sociedade.

\section{Referências}

Bardin, L. (2009). Análise de conteúdo. Lisboa: Edições 70.

Bastos, A., Pinho, A., \& Costa, C. (1995). Significado do trabalho: um estudo entre trabalhadores inseridos em organizações formais. Revista de Administração de Empresas, 35 (6), 20-29.

Bitencourt, B., Gallon, S., Batista, M., \& Piccinini, V. (2011). Para além do tempo de emprego: o sentido do trabalho no processo de aposentadoria. Revista de Ciências da Administração, 13 (31), 30-57.

Celeguim, C., \& Roesler, H. (2009). A invisibilidade social no âmbito do trabalho. Revista Interação, 3 (1), 12-26.

Coelho, E. C. (1999). As profissões imperiais: advocacia, medicina e engenharia no Rio de Janeiro, 1822-1930. Rio de Janeiro: Record.

Costa, F. (2004). Homens invisíveis: relatos de uma humilhação social. São Paulo: Globo.

Costa, F. (2008). Moisés e Nilce: retratos biográficos de dois garis: um estudo de psicologia social a partir de observação participante e entrevistas. Tese de Doutorado, Faculdade de Psicologia, Universidade de São Paulo. São Paulo - SP.

Dantas, M. (2014). Sabores doces: uma análise sociocultural da doçaria do Seridó Potiguar. In Anais da XXIX Reunião Brasileira de Antropologia. (pp. 1-19). Natal (RN). Recuperado de https://bit.ly/2ZKbdbd

Dejours, C. (2004). Subjetividade, trabalho e ação. Production, 14 (3), 27-34. 
Diniz, A., Carrieri, A., \& Barros, A. (2013). Invisibilidade social e trabalho noturno: reflexões a partir de representações sociais de garçons. Gestão e Planejamento, 14 (1), 348-360.

Diogo, M. (2007). Os sentidos do trabalho de limpeza e conservação. Psicologia em Estudo, 12 (3), 483-492.

Dourado, D., Holanda, L., Silva, M., \& Bispo, D. (2009). Sobre o sentido do trabalho fora do enclave de mercado. Cadernos Ebape.BR, 7 (2), 349-367.

Flick, U. (2002). Entrevista episódica. In: Bauer, M. \& Gaskell, G. Pesquisa qualitativa com texto, imagem e som: um manual prático. Petrópolis, RJ: Vozes.

Gallon, S., Bitencourt, B., Viana, D., \& Antonello, C. (2016). Formas de aprendizagem e saberes no trabalho de manicures. Pensamento Contemporâneo em Administração, 10 (1), 96-112.

Glanzner, C., Olschowsky, A., \& Kantorski, L. (2011). O trabalho como fonte de prazer: avaliação da equipe de um centro de atenção psicossocial. Revista da Escola de Enfermagem da USP, 45 (3), 716-721.

Godoy, A. (1995). Pesquisa qualitativa: tipos fundamentais. Revista de Administração de Empresas, 35 (3), 20-29.

Godoy, A. (2005). Refletindo sobre critérios de qualidade da pesquisa qualitativa. Revista Eletrônica de Gestão Organizacional, 3 (2), 81-89.

Hackman, J., \& Oldham, G. (1975). Development of the job diagnostic survey. Journal of Applied Psychology, 60 (2), 159-170.

Lourenço, C. (2014). O cliente "não tem sempre razão": o trabalho precário nas relações entre consumidores e comerciários. In F. Naves (Org.). Trabalho e trabalhadores nas sociedades contemporâneas: outras lentes sobre invisibilidades construídas (pp. 21-40). Rio de Janeiro: Elsevier.

Medeiros, L., \& Macedo, K. (2006). Catador de material reciclável: uma profissão para além da sobrevivência? Psicologia ES Sociedade, 18 (2), 62-71.

Morin, E. (2001). Os sentidos do trabalho. Revista de Administração de Empresas, 41 (3), 8-19.

Morin, E., Tonelli, M., \& Pliopas, A. (2007). O trabalho e seus sentidos. Psicologia Eु Sociedade, 19, 47-56.

Meaning of Work International Research Team (MOW). (1987). The meaning of work. London: Academic Press.

Nascimento, R., Santos, A., \& Pinho, A. (2017). O sentido do trabalho para o agente funerário. In Anais do XLI Encontro da Associação Nacional de Pós-Graduação e Pesquisa em Administração (pp. 1-16). São Paulo. Recuperado de https://bit.ly/2RB5OAo

Oliveira, S. R., Piccinini, V. C., Fontoura, D. S., \& Schweig, C. (2004). Buscando o sentido do trabalho. In Anais do XXVIII Encontro da Associação Nacional de Pós-Graduação e Pesquisa em Administração. (pp. 1-16). Porto Alegre. Recuperado de https://bit.ly/2N9QADN

Piccinini, V., Oliveira, S., Fontoura, D., \& Schweig, C. (2005). Quando trabalhar faz sentido. Paris: AGRH.

Rohm, R., \& Lopes, N. (2015). O novo sentido do trabalho para o sujeito pós-moderno: uma abordagem crítica. Cadernos EBAPE.BR, 13 (2), 332-345.

Rose, M. (2007). O Saber no trabalho: valorização da inteligência do trabalhador. São Paulo: Senac.

Santos, W. (2015). Uma reflexão necessária sobre a profissão docente no Brasil, a partir dos cinco tipos de desvalorização do professor. Sapere Aude, 6 (11), 349-358.

Silva, N., \& Tolfo, S. (2012). Trabalho significativo e felicidade humana: explorando aproximações. Psicologia: organizações e trabalho, 12 (3), 341-354.

Silva, J., Melo, N., \& Vasconcelos, A. (2014). A astúcia invisível de mulheres trabalhadoras de escola. Psicologia em Revista, 20 (3), 427-445.

Silva, M., \& Simões, J. (2015). O estudo do sentido do trabalho: contribuições e desafios para as organizações contemporâneas. Revista Capital Científico, 13 (3).

Teixeira, E., \& Lorenzzon, G. (2016). Saúde mental e trabalho: um estudo com agricultores orgânicos no sudoeste do Paraná. Revista Grifos, 24 (38/39), 179-198.

Tolfo, S., \& Piccinini, V. (2007). Sentidos e significados do trabalho: explorando conceitos, variáveis e estudos empíricos brasileiros. Psicologia Eु Sociedade, 19, 38-46.

Ulmann, A. (2014). O trabalho na creche a partir do invisível. Caderno de Psicologia Social do Trabalho, 17 (1), 119-128. 
Ventura, T. (2011). Luta social por reconhecimento: dilemas e impasses na articulação pública do desrespeito. Revista de Sociologia e Política, 19 (40), 159-170.

Vilas Boas, A. A., \& Morin, E. M. (2014). Sentido do trabalho e fatores de qualidade de vida no trabalho para professores de universidades públicas do Brasil e do Canadá. Anais do XXXVIII Encontro Nacional da Associação Nacional de Pós-graduação e Pesquisa em Administração. (pp. 1-16). Rio de Janeiro. Recuperado de https://bit.ly/2xoQKwJ

Wadsworth, E., Chaplin, K., \& Smith, A. (2010). The work environment, stress and well-being. Occupational Medicine, $60(8), 635-639$.

Zanelli, J. C., Silva, N., \& Soares, H. (2010). Orientação para aposentadoria nas organizações: projetos para o pós-carreira. Porto Alegre: Artmed.

\section{Endereço para correspondência}

rosianedutramartins@gmail.com,priscilacerutti@yahoo.com.br, elemduarte@yahoo.com.br, shalimargallon@gmail.com
Recebido em: 20/02/2018

Revisado em: 16/10/2018

Aprovado em: 16/02/2019 